\title{
Produção e purificação de imunoglobulinas Y policlonais anti-Leptospira spp. ${ }^{1}$
}

\author{
Tatiane C.F. Tavares ${ }^{2 *}$, Pollyanna M. Soares², João H.F.F. Neves ${ }^{3}$, Mayara M. Soares ${ }^{2}$, Álvaro \\ F. Junior ${ }^{4}$, Dayane L.N. de Souza ${ }^{5}$, Veridiana M.R. Ávila ${ }^{5}$ e Anna M.C. Lima-Ribeiro ${ }^{2}$
}

\begin{abstract}
Tavares T.C.F., Soares P.M., Neves J.H.F.F., Soares M.M., Ferreira Junior Á., Souza D.L.N., Ávila V.M.R. \& Lima-Ribeiro A.M.C. 2013. [Production and purification of polyclonal anti-Leptospira immunoglobulin Y.] Produção e purificação de imunoglobulinas Y policlonais anti-Leptospira spp. Pesquisa Veterinária Brasileira 33(9):1097-1102. Centro Colaborador de Defesa Agropecuária do Brasil Central, Universidade Federal de Uberlândia, Faculdade de Medicina Veterinária e Zootecnia, Rua Ceará s/n, Bloco 2D, sala 33, Uberlândia, MG 38400-902, Brazil. E-mail: tcftavares@yahoo.com.br

The aim was to determine whether hens immunized with an inactivated suspension of Leptospira and a solution of outer membrane proteins extracted from the serovar Hardjo, could produce specific polyclonal antibodies to Leptospira, detected in ELISA assay. Eight hens White Leghorn race with 25 -weeks-old were immunized, three with an inactivated suspension of Leptospira, three with a solution of outer membrane proteins (OMP) extracted from the serovar Hardjo and two controls immunized with saline. Blood samples were collected fortnightly and eggs daily. The IgY was purified from the egg yolk using the method for the delipidation of dilution with water acidic and ammonium sulfate precipitation. The ELISA assay was performed to verify the specificity of the IgY, these was possible to observe the production of specific antibody to Leptospira both in serum and purified egg yolk. The specific antibody titers peaked in the fifth week post immunization. The production of polyclonal IgY was effective for producing high titers of specific antibodies.
\end{abstract}

INDEX TERMS: Hens, Leptospira interrogans, leptospirosis, immunoglobulin Y.

RESUMO.- Objetivou-se verificar se galinhas imunizadas com uma solução de Leptospira interrogans inativadas e proteínas de membrana externa do sorovar Hardjo, poderiam produzir anticorpos policlonais específicos anti-leptospiras, detectáveis em testes ELISA. Foram imunizados oito galinhas com 25 semanas de idade, da raça White Leghorn, sendo três imunizadas com uma suspensão de lep-

\footnotetext{
${ }^{1}$ Recebido em 15 de maio de 2013.

Aceito para publicação em 5 de agosto de 2013.

${ }^{2}$ Centro Colaborador de Defesa Agropecuária do Brasil Central, Faculdade de Medicina Veterinária e Zootecnia (FMVZ), Universidade Federal de Uberlândia (UFU), Avenida Ceará s/n, Bloco 2D, sala 33, Campus Umuarama, Uberlândia, MG 38400-902, Brasil. *Autor para correspondência: tcftavares@yahoo.combr

${ }^{3}$ Universidade Federal de Minas Gerais (UFMG), Campus Pampulha, Av. Antônio Carlos 6627, Cx. Postal 567, Belo Horizonte, MG 30123-970, Brasil.

${ }^{4}$ Instituto de Estudos Avançados em Veterinária José Caetano Borges, sala 2A101, Campus Aeroporto, Av. Nenê Sabino 1801, Bairro Universitário, Uberaba, MG 38055-500, Brasil.

${ }^{5}$ Laboratório de Química de Proteínas e Produtos Naturais, Instituto de Genética e Bioquímica (INGEB), UFU, sala 32, Bloco E, Av. Ceará s/n, Campus Umuarama, Uberlândia, MG 38400-902.
}

tospiras inativadas, três com uma solução de proteínas de membrana externa extraída do sorovar Hardjo e duas controle. Coletas de sangue foram realizadas quinzenalmente e de ovos diariamente. A IgY foi purificada a partir da gema dos ovos utilizando para a delipidação o método de diluição em água ácida e a precipitação com sulfato de amônio. Nos testes ELISA realizados para verificar a especificidade da IgY, foi demonstrada a produção de anticorpos anti-Leptospira, tanto no soro quanto nas gemas purificadas. 0 pico de produção de anticorpos específicos ocorreu na $5^{\underline{0}}$ semana após a primeira imunização. Ficou demonstrada a possibilidade da indução da produção de anticorpos específicos em galinhas imunizadas com leptospiras do sorovar Hardjo inativadas, bem como, com proteínas de membrana externa (PME) extraidas desse sorovar. As galinhas imunizadas com uma suspensão de leptospiras inativadas ou com PME de Leptospira interrogans do sorovar Hardjo produziram anticorpos reativos a PME Hardjo detectáves por teste ELISA.

TERMOS DE INDEXAÇÃO: Galinhas, gema de ovos, Leptospira interrogans, leptospirose, imunoglobulinas Y. 


\section{INTRODUÇÃO}

Os anticorpos são moléculas com elevada especificidade para a ligação e inativação de substâncias externas, tais como moléculas tóxicas ou antígenos, que podem penetrar no organismo de animais vertebrados (Karlsson et al. 2004). Em razão disto, tem sido utilizados para fins diagnósticos, terapêuticos e inclusive para a inativação de substâncias (Reilly et al. 1996).

Os anticorpos específicos, policlonais ou monoclonais, atualmente disponíveis para pesquisa, diagnóstico e terapias são obtidos principalmente de mamíferos com especial destaque para os coelhos e ratos, (Narat 2003).De maneira alternativa, os anticorpos purificados da gema de ovos de galinhas imunizadas, denominados imunoglobulinas $\mathrm{Y}$ ou IgY (do inglês yolk = gema), têm apresentado várias aplicações, em imunodiagnóstico, imunoterapia e estudos de proteômica (Karlsson et al. 2004).

As vantagens da utilização dos anticorpos IgY policlonais em relação aos do tipo IgG de mamíferos incluem a redução do número de animais imunizados, a elevada quantidade de anticorpos purificados por $\mathrm{mL}$ de gema sem a sangria da galinha, bem como o baixo custo a fácilidade de execução (Schade et al. 1996, Karlsson et al. 2004). Destaque-se ainda que com os anticorpos IgY elimina-se a ocorrência de resultados falsos-positivos sempre possíveis nas técnicas de imunoensaio que empregam amostras de soro ou células de mamíferos, pois não sofrem a interferência do fator reumatóide, não fixam complemento e não interagem com os receptores para Fc dos mamíferos. Ressalte-se também que em relação à purificação, os anticorpos IgY não se ligam às proteínas A e B, respectivamente, de Staphylococcus spp. e Streptococcus spp (Tini et al. 2002, Carlander et al. 2002, Zhang 2003).

A distância filogenética entre aves e mamíferos permite a produção de anticorpos contra proteínas altamente conservadas de mamíferos (Larsson et al. 1998). Além disso, os anticorpos de aves reconhecem epítopos diferentes dos de mamíferos o que aumenta o número de anticorpos distintos e consequentemente a possibilidade de ligações (Carlander et al. 1999, Ferreira Júnior et al. 2012).

0 presente trabalho teve por objetivo a verificação dos níveis de anticorpos policlonais anti-leptospiras, em testes ELISA aplicados ao soro sanguíneo de galinhas imunizadas com uma estirpe de L.interrogans do sorovar Hardjo apresentada sob a forma de leptospiras integras inativadas ou de apenas proteínas da membrana externa do microrganismo.

\section{MATERIAL E MÉTODOS}

A pesquisa foi realizada no Laboratório de Doenças Infecto-contagiosas da Universidade Federal de Uberlândia (LADO-UFU) e no Laboratório de Bioquímica do Instituto de Genética e Bioquímica da Universidade Federal de Uberlândia (INGEB-UFU).

Os anticorpos foram produzidos pela imunização de galinhas com dois tipos de antígenos: suspensão de 14 sorovares de Leptospiras íntegras inativadas (bactérias totais) e apenas a proteína de membrana externa (PME) de Leptospira interrogans sorovar Hardjo.

Para obtenção do antígeno, foram utilizadas estirpes (bactérias totais) de Leptospira interrogans fornecidas pelo Laborató- rio de Doenças Infectocontagiosas FAMEV-UFU. Para o preparo de uma suspensão de Leptospiras inativadas, as bactérias foram cultivadas em caldo EMJH (meio Ellinghausen e McCullough modificado por Johnson e Harris, 1967) por sete a dez dias em estufa bacteriológica com temperatura de 28 a $29^{\circ} \mathrm{C}$ (Faine, 1999).

Após atingir a densidade de 1 a $2 \times 10^{8}$ leptospiras $/ \mathrm{mL}$, os cultivos foram centrifugados a $13.000 \mathrm{rpm}$ durante 30 minutos, o pellet contendo as leptospiras (14 sorovares de L.interrogans: Australis, Autumnalis, Bataviae, Bratislava, Canicola, Copenhageni, Grippotyphosa, Hardjo, Hebdomadis, Icterohaemorrhagiae, Pomona, Pyrogenes, Tarassovi e Wolffi) foi diluído em PBS ( $\mathrm{NaCl}$ $\left.137 \mathrm{mM}, \mathrm{KCl} 2,7 \mathrm{mM}, \mathrm{Na}_{2} \mathrm{HPO}_{4} 12 \mathrm{mM}, \mathrm{K}_{2} \mathrm{HPO}_{4} 1,2 \mathrm{mM}, \mathrm{pH} 7,4\right)$ estéril, e comparada com o valor 0,5 da escala de Macfarland para que fosse atingida a densidade final aproximada de $1 \times 10^{8}$ leptospiras $/ \mathrm{mL}$, e em seguida as bactérias foram inativadas a $56^{\circ} \mathrm{C}$ por 16-18 horas (Surujballi \& Elmgren 2000).

A extração de proteínas de membrana externa (PME) de Leptospira interrogans sorovar Hardjo foi realizada utilizando-se a metodologia descrita por Haake et al. (1991). Um cultivo de $L$. interrogans sorovar Hardjo com sete dias de crescimento foi centrifugado a $13.000 \mathrm{xg}$ a $4^{\circ} \mathrm{C}$, durante dez minutos, o sobrenadante foi então descartado e o pellet ressuspendido em PBS pH 7, 4 acrescido de $5 \mathrm{mM} \mathrm{MgCl}_{2}$, por três vezes consecutivas. Posteriormente o pellet foi ressuspendido em TE $(10 \mathrm{mM}$ de Tris hidroclorido, 2mM EDTA), pH 7,4, adicionado de 1\% de TritonX114 (v/v) (Sigma-Aldrich). A suspensão foi incubada a $4^{\circ} \mathrm{C}$ por 30 minutos e a seguir foi centrifugada a $17.000 \mathrm{xg}$, a $4^{\circ} \mathrm{C}$ durante dez minutos, o pellet foi descartado e foi adicionado $2 \%$ de Triton X114 (v/v) ao sobrenadante, que após aquecimento a $37^{\circ} \mathrm{C}$ por dez minutos, foi centrifugado a $2.000 \mathrm{xg}$ por dez minutos a temperatura ambiente.

Após a centrifugação as duas fases presentes, aquosa e detergente, foram separadas e submetidas a um banho de gelo por dez minutos. Acrescentou-se a fase aquosa $2 \%$ de Triton X114 (v/v) e a fase detergente nove partes do tampão TE, $\mathrm{pH} 7,4$, incubou-se por dez minutos a $37^{\circ} \mathrm{C}$ e depois centrifugou-se a $2.000 \mathrm{xg}$ por dez minutos a temperatura ambiente. Os procedimentos de separação de fases, resfriamento, adição de reagentes, aquecimento e centrifugação foram repetidos quatro vezes. As fases detergente e aquosa foram então separadas.

As duas frações foram precipitadas em acetona segundo Cunningham et al. (1988), adicionou-se 10 vezes o volume de acetona (Vetec, PA) e incubou-se no gelo por 45 minutos. Após incubação as frações foram centrifugadas a $14.000 \mathrm{xg}$, a $4^{\circ} \mathrm{C}$, por 30 minutos. A acetona presente no sobrenadante foi então descartada e o pellet ressuspendido em PBS e estocado a $-20^{\circ} \mathrm{C}$.

Foram imunizadas oito galinhas poedeiras da linhagem White Leghorn, com 25 semanas de idade, cedidas pela granja Planalto de Uberlândia-MG, as quais foram divididas aleatoriamente em três grupos experimentais (Quadro 1). 0 esquema de imunizações foi realizado de acordo com Barbas et al. (2001).

As imunizações foram realizadas com intervalos de 15 dias, sendo que na primeira foi empregado o adjuvante completo de Freund (Sigma) e nas demais o adjuvante incompleto de Freund (Sigma), correspondendo a $50 \%$ do volume total da solução. Fo-

Quadro 1. Grupos experimentais e tipo de imunização utilizada, Uberlândia, 2012

\begin{tabular}{ccl}
\hline Grupo & n & \multicolumn{1}{c}{ Imunização } \\
\hline 1 & 2 & $\begin{array}{l}\text { PBS + Adjuvante* } \\
\text { Suspensão de Leptospiras inativadas diluídas em } \\
2\end{array}$ \\
3 & $\begin{array}{l}\text { PBS + Adjuvante* } \\
\text { Solução de proteínas de membrana externa sorovar } \\
\text { Hardjo diluídas em PBS + Adjuvante* }\end{array}$
\end{tabular}

$\bar{*}$ Adjuvante de Freund (Sigma Chemical Co.). 
ram inoculados $500 \mu \mathrm{L}(250 \mu \mathrm{l}$ do antígeno diluído em PBS e $250 \mu \mathrm{l}$ de adjuvante) profundamente no músculo peitoral da galinha, dividindo-se o volume total em quatro pontos diferentes. 0 acompanhamento para avaliação de reações pós-vacinais foi realizado diariamente durante todo o período experimental.

0 Grupo 1 foi imunizado quatro vezes com $250 \mu$ l de PBS, enquanto Grupo 2 foi imunizado quatro vezes com $250 \mu \mathrm{l}$ da suspensão de leptospiras inativadas (densidade de $1 \times 10^{8}$ células $/ \mathrm{mL}$ ) e o Grupo 3 três vezes com $200 \mu$ g de PME diluída em $250 \mu$ de PBS.

Foram realizadas coletas de sangue quinzenais, $1 \mathrm{~mL}$ na asa (veia ulnar). Os ovos foram coletados diariamente a partir de uma semana antes da inoculação (pré-inoculação). Após a coleta, os ovos foram separados por semana, e estocados a $4^{\circ} \mathrm{C}$ até a realização do processo de delipidação.

Na purificação das imunoglobulinas IgY policlonais totais, as gemas dos ovos foram cuidadosamente separadas da clara e lavadas com água ultrapura para a remoção de resíduos de clara (Bizanov \& Jonauskiené, 2003). Em seguida, a membrana vitelínica foi rompida e a gema foi coletada em frascos cônicos de $50 \mathrm{~mL}$, os quais foram armazenados a $-20^{\circ} \mathrm{C}$ até o momento da purificação. Ao final do procedimento, obteve-se um pool semanal de gemas para cada um dos três grupos de galinhas imunizadas.

A purificação dos anticorpos IgY totais iniciou-se pela delipidação, remoção da fração lipídica da gema, (Akita \& Nakai 1993). A gema pura foi diluída com água ultrapura na proporção 1:10 (v/v), após a homogeneização o pH da mistura foi ajustado para uma faixa entre 5,0-5,2, por meio de gotejamento de $\mathrm{HCl} 0,1 \mathrm{~N}$ e, em seguida, a mistura acidificada foi armazenada a $4^{\circ} \mathrm{C}$ overnight. Após esse período a solução foi centrifugada a $10.000 \mathrm{xg}$ por 25 minutos a $4^{\circ} \mathrm{C}$. 0 pellet contendo a fração rica em lipídeos foi descartado e o sobrenadante contendo os anticorpos totais, foi filtrado (filtro de $0,45 \mu \mathrm{m}$ Millipore). A amostra filtrada teve seu $\mathrm{pH}$ ajustado para 7,4 com PBS $10 x$ e após isso foi armazenada a $-20^{\circ} \mathrm{C}$.

Após a delipidação, foi realizada a precipitação com sulfato de amônio Synth (Araújo et al. 2010) o sulfato foi adicionado a amostra filtrada na concentração de $20 \%$ (p/v) sob agitação durante 30 minutos a $4^{\circ} \mathrm{C}$. Após esse tempo o material foi centrifugado a $2.000 x$ g por 30 minutos a $4^{\circ} \mathrm{C}$, o sobrenadante foi descartado e o pellet ressuspendido em PBS $1 \mathrm{x}, \mathrm{pH} 7,4$.

As amostras foram diálisadas em uma membrana de AMICOM (Amicom Ultra-15 Centrifugal Filter Unit Millipore), centrifugando-se a amostra juntamente com PBS, pH 7,4 a 4.000xg por 30 minutos, $4^{\circ} \mathrm{C}$, por três vezes.

Após o término da extração das imunoglobulinas IgY totais, a concentração proteica foi obtida em todas as frações por meio do método de Bradford (1976) e a pureza das preparações foi investigada por eletroforese unidimensional em gel de poliacrilamida a $16 \%$ (p/v), aplicando-se $10 \mu \mathrm{g}$ de amostra por poço. A visualização das bandas proteicas foi efetuada com a coloração do gel com Coomassie Blue R250 (Sigma).

Para confirmar a produção de anticorpos IgY anti-leptospira utilizou-se como antígeno no ELISA apenas a PME de Leptospira interrogans sorovar Hardjo, segundo Souza et al. 2002. Duas placas de microtitulação de poliestireno (MaxiSorp, Nunc) foram sensibilizadas com $50 \mu \mathrm{L}$ /poço de proteínas de Membrana Externa do sorovar Hardjo a uma concentração de $10 \mu \mathrm{g} / \mathrm{mL}$ em tampão carbonato-bicarbonato $\left(\mathrm{NaHCO}_{3} 0,1 \mathrm{M}, \mathrm{pH} 8,6\right)$ e incubadas durante a noite a $4^{\circ} \mathrm{C}$. Em seguida os sítios remanescentes para ligações inespecíficas foram bloqueados com tampão Tris- $\mathrm{HCl}$ acrescido de leite em pó desnatado na concentração de $5 \%(\mathrm{p} / \mathrm{v})$ (TBS-M), durante 2 horas a $37^{\circ} \mathrm{C}$. Após a incubação foram realizadas três lavagens com tampão TBS.

Amostras de $50 \mu \mathrm{L}$ das IgY totais, correspondentes ao pool de gemas por semana do experimento de imunização, diluídas a 1:50 em TBS acrescido de 0,05\% de Tween 20 e 5\% de leite em pó desnatado (TBS-TM), foram incubadas por 60 minutos a $37^{\circ} \mathrm{C}$. Após esse procedimento um segundo ciclo de lavagens idêntico foi executado. A detecção de IgY foi efetuada pela incubação com anticorpos IgG de coelho anti-IgY marcados com peroxidase (Sigma) diluídos 1:5000 em PBS-TM por 60 minutos, $37^{\circ} \mathrm{C}$. Foi realizado um último ciclo de lavagens e, em seguida, foi efetuada a revelação com a adição de $50 \mu \mathrm{L} /$ poço de orto-fenilenodiamina (OPD) (DAKO) acrescido de $\mathrm{H}_{2} \mathrm{O}_{2}$ a 30\%. Decorridos 15 minutos a temperatura ambiente e ao abrigo da luz, a reação foi interrompida com a adição de $25 \mu \mathrm{L} /$ poço de $\mathrm{H}_{2} \mathrm{SO}_{4}(2 \mathrm{~N})$, efetuando-se em seguida a leitura a $492 \mathrm{~nm}$ em espectrofotômetro de microplaca (Thermo Plate, TP-Reader).

\section{RESULTADOS E DISCUSSÃO}

A eletroforese da IgY purificada das gemas de ovos (Fig.1) demonstrou que o processo de purificação com sulfato de amônio a $20 \%$ não foi totalmente eficiente, uma vez que houve a formação de outras bandas além da de IgY, resultado que discorda do obtido por Svendsen et al. 1995 e por Araújo 2007 Foi constatado que a banda de IgY, encontrava-se um pouco abaixo de $200 \mathrm{Kd}$, de fato tem ocorrido divergências quanto ao PM da IgY, Carlander (2002) e Chacana et al. (2004) afirmaram que esta molécula apresenta 167,25 kDa enquanto Leslie e Clem (1969) encontraram um peso molecular de até $206 \mathrm{kDa}$, e Devi et al. (2002) estabeleceram o seu peso em $190 \mathrm{kDa}$, no entanto foi estabelecido a maioria dos autores concorda que o peso esteja situado em torno de $180 \mathrm{Kd}$ (Warr et al. 1995, Akita et al. 1998, Bizanov et al. 2004).

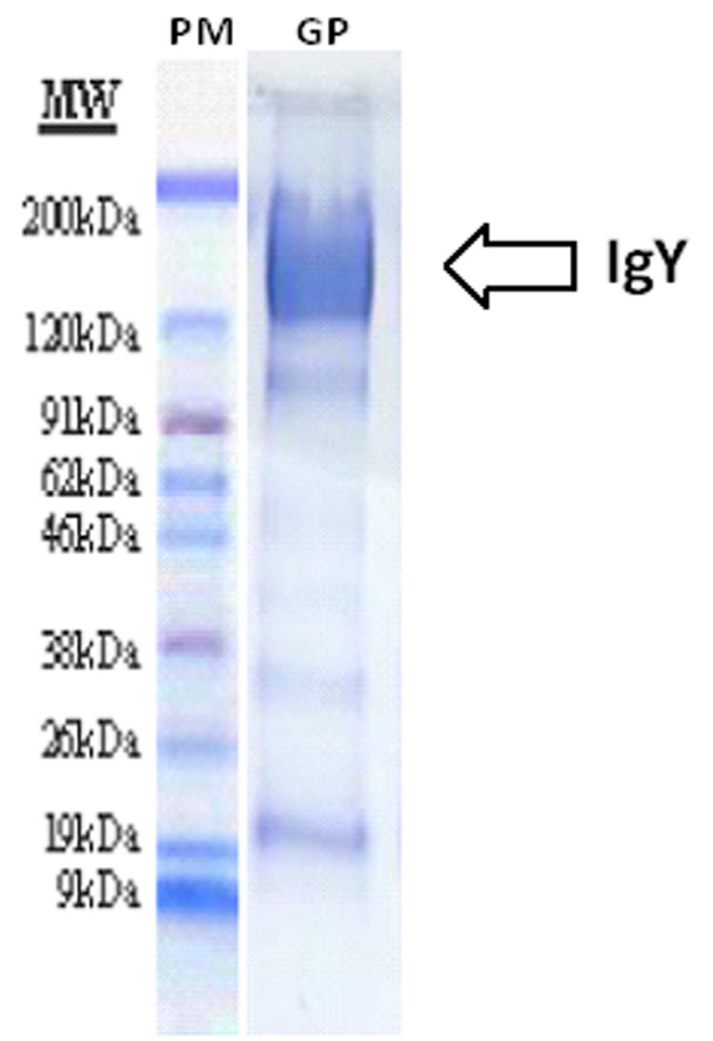

Fig.1. Perfil eletroforético da IgY das gemas de ovos purificadas com sulfato de amônio. PM = Padrão de peso molecular (Amresco), GP = gema purificada. 
A partir da segunda semana de imunização houve um aumento no título de anticorpos específicos anti-PME e anti-Leptospira do sorovar Hardjo (Fig.2), embora esta resposta tenha sido baixa o resultado obtido se assemelha aos encontrados por Almeida et al. (1998) que observaram aumento do título de anticorpos após a segunda imunização.

A atividade dos anticorpos do grupo controle foi baixa e permaneceu inalterada durante todo o experimento. 0 que indica que sua atividade específica foi insignificante e, portanto, poderia ser empregada como um controle negativo em experiências subsequentes.

A Figura 3 mostra o perfil cinético da resposta imunológica observada na gema durante as dez semanas trabalhadas.

Na $4^{a}$ semana, duas semanas após a segunda imunização houve um aumento considerável no título de anticorpos, resultado que confirma o descrito por Narat (2003) que relatou que a presença de anticorpos na gema deve ser verificada após a segunda imunização.

Os títulos de anticorpo anti-PME e anti-Lepto nas gemas de ovos atingiram o pico na quinta semana após a inoculação. 0 perfil cinético encontrado diferiu do observado por Bizanov \& Jonauskiene (2003) e Bizhanov, Jonauskiene \& Hau (2004),que constataram inicio da elevação do título a

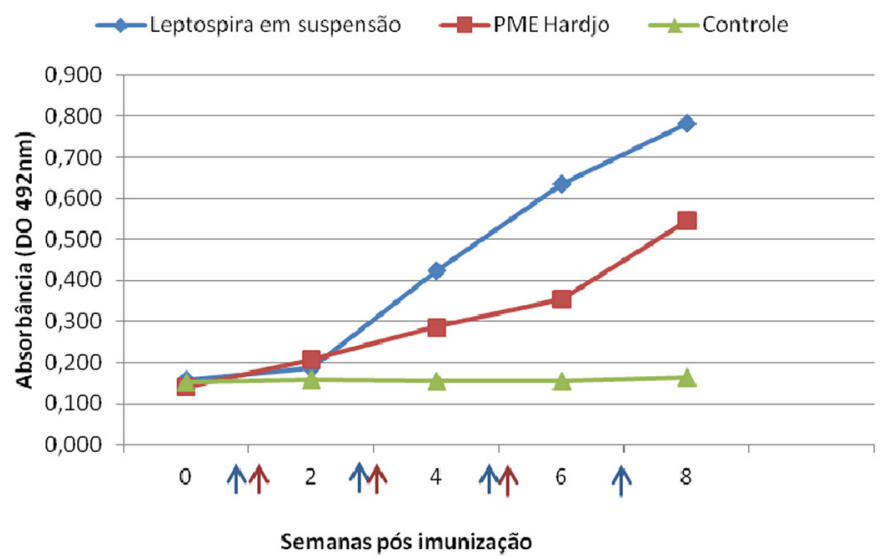

Fig.2. Curva de absorbância de IgY nas amostras de soro de galinhas obtidas pelo teste ELISA durante 8 semanas pós imunização.

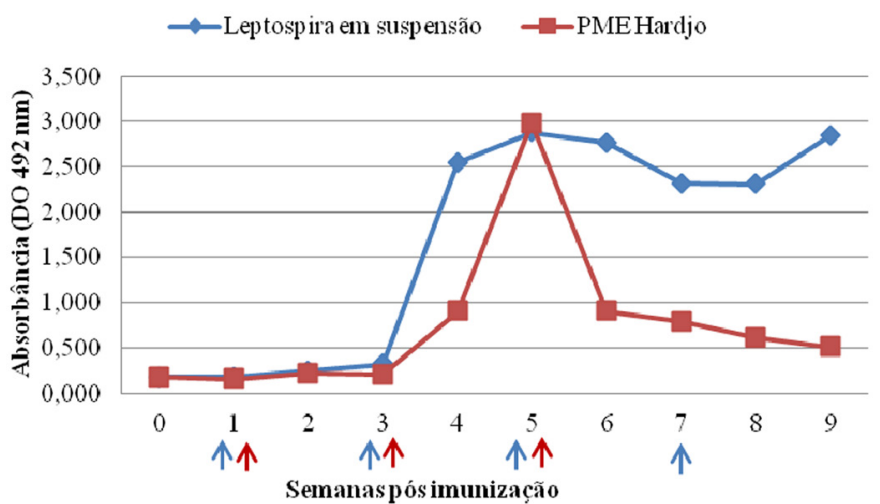

Fig.3. Cinética de produção de IgY nas amostras de gema de ovo de galinhas obtida pelo teste ELISA durante 10 semanas. As setas vermelhas indicam as imunizações com PME e as setas azuis as imunizações com Leptospira em suspensão. partir da segunda semana de imunização e aumento constante nas semanas subsequentes. Tais divergências poderiam ser atribuídas a diferenças da imunogenicidade dos antígenos empregados, bem como da utilização de diferentes esquemas de vacinação, raças de galinhas distintas e tipos de ensaios empregados (Bizhanov \& Vyshniauskis 2000). No entanto o perfil observado no presente trabalho se assemelhou ao encontrado por Paul et al. (2007) e por Araújo et al. (2010), que registraram aumento significativo de anticorpos especificos apenas após a segunda inoculação, com pico de anticorpos respectivamente na quarta ou quinta semana de imunização.

No grupo inoculado com PME houve queda acentuada na produção de anticorpos após a $7^{\mathrm{a}}$ semana, provavelmente, isso se deva ao fato de terem sido realizadas apenas três inoculações enquanto no grupo inoculado com suspensão de leptospiras foram realizadas quatro inoculações. Contudo não podem ser excluído a possível influência de diferenças de imunogenicidade dos antígenos (Bizhanov \& Vyshniauskis, 2000). Chen et al. (2002) e Pauly et al. (2009) destacaram que a queda na concentração de anticorpos, não é um fenômeno desejado, e que a sua ocorrência pode ser revertida por meio da reaplicação do antígeno.

Quando se compara a resposta sérica e a resposta na gema observa-se que a detecção de anticorpos na gema ocorre com um atraso de aproximadamente sete dias, depois da detecção sérica, fato que pode ser explicado em virtude do tempo requerido para o desenvolvimento do folículo ovariano e ovopostura (Pei \& Collisson 2005, Davison et al. 2008, Ferreira Júnior et al. 2012).

Tanto as galinhas imunizadas com a suspensão de leptospiras inativadas de 14 diferentes sorovares, quanto os animais tratados com PME de Leptospira interrogans do sorovar Hardjo produziram anticorpos reconhecidos pelo PME de Leptospira interrogans sorovar Hardjo, utilizado como antígeno no ELISA. Lafetá (2006) observou que o perfil protéico das proteínas de membrana externa da Leptospira interrogans sorovar Hardjo possui muitas similaridades com o perfil protéico da membrana externa de $L$. interrogans. Souza et al. (2012) demonstrou que um teste ELISA utilizando PME do sorovar Hardjo apresentou sensibilidade de $100 \%$, especificidade $73 \%$ e concordância de 83\% quando comparado a Soroaglutinação Microscópica.

Por demonstrarem afinidade às proteínas de membrana externa (PME) de Leptospira interrogans sorovar Hardjo, os anticorpos produzidos em galinhas desta pesquisa, poderiam ser utilizados em testes diagnósticos para leptospirose. Tini et al. (2002) ressaltaram que a IgY pode ser usada em praticamente todos os métodos de imunodiagnóstico tradicionalmente desenvolvidos com IgG de mamíferos ou seja, imunofluorescência, ELISA, técnicas de imunoeletroforese, Western blotting, imuno-histoquímica, e muitos outros (Tini et al. 2002).

Esses resultados reforçam os obtidos anteriormente onde já foram caracterizados como bons antígenos e imunógenos várias PME de Leptospira (Haake et al. 2000, Cullen et al. 2003, Koizumi \& Watanabe 2005, Matsunaga et al. 2006, Palaniappan et al. 2007), sendo que o diferencial desse estudo foi a utilização de imunoglobulinas (IgY) pro- 
duzidas em galinhas anti-Leptospira e anti-PME de Leptospira.

\section{CONCLUSÃO}

Galinhas imunizadas com uma suspensão de Leptospiras inativadas e com PME de Leptospira interrogans do sorovar Hardjo produziram anticorpos reativos a PME Hardjo detectáveis por teste ELISA.

Agradecimentos.- Ao Conselho Nacional de Desenvolvimento Científico e Tecnológico (CNPq) juntamente ao Ministério da Agricultura, Pecuária e Abastecimento (MAPA) e à Secretaria de Defesa Agropecuária (SDA), pelo apoio financeiro proveniente da aprovação do edital no $64 / 2008$ CNPq/ MAPA/DAS, e à Fundação de Amparo à Pesquisa do Estado de Minas Gerais (FAPEMIG) que também nos deu apoio financeiro.

\section{REFERÊNCIAS}

Akita E.M., Li-Chan E.C. \& Nakai S. 1998. Neutralization of enterotoxigenic Escherichia coli heat-labile toxin by chicken egg yolk immunoglobulin $\mathrm{Y}$ and its antigen-binding fragments. Food Agricult. Immunol. 10:161-172.

Akita E.M. \& Nakai S. 1993. Comparison of four purification methods for the production of immunoglobulins from eggs laid by hens immunized with an enterotoxigenic E. coli strain. J. Immunol. Methods 160:207-214.

Almeida C.M.C., Kanashiro M.M., Rangel Filho F.B., Mata M.F., Kipnis T.L. \& Da Silva W.D. 1998. Development of snake antivenom antibodies in chicken and their purification from yolk. Vet. Rec. 143:579.

Araújo A.S. 2007. Produção de antiveneno botrópico em ovos de galinha. Dissertação de Mestrado em Ciência Animal, Escola de Veterinária, Universidade Federal de Minas Gerais, Belo Horizonte, MG. 57p.

Araujo A.S., Lobato Z.I.P., Chávez-Olórtegui C. \& Velarde D.T. 2010. Brazilian IgY-Bothrops antivenom: Studies on the development of a process in chicken egg yolk. Toxicon 55:739-744.

Barbas III C.F., Burton D.R., Scott J.K. \& Silverman G.J. 2001. Phage Display: a laboratory manual. Plain View, Cold Spring Harbor Laboratory Press, New York.

Bizanov G. \& Jonauskiené I. 2003. Production and purification of IgY from egg yolk after immunization of hens with pig IgG. Bull. Vet. Inst. Pulawy 47:403.

Bizanov G., Jonauskiené I. \& Hau J. 2004. A novel method, based on lithium sulfate precipitation for purification of chicken egg yolk immunoglobulin Y, applied to immunospecific antibodies against Sendai virus. Scand. J. Lab. Anim. Sci. 31:121.

Bizhanov G. \& Vyshniauskis G. 2000. A comparison of three methods for extracting IgY from the egg yolk of hens immunized with Sendai virus. Vet. Res. Commun. 24:103-113.

Bradford M.M. 1976. A rapid and sensitive method for the quantification of microgram quantities of protein utilizing the principle of protein-dye binding. Analyt. Biochem. 72:248-254.

Carlander D. 2002. Avian IgY antibody: in vitro and in vivo. Tese de Doutorado em Quimica Clinica, Uppsala University, Sweden. 53p.

Carlander D., Kollberg H., Wejåker P.E. \& Larsson A. 1999. Prevention of chronic Pseudomonas aeruginosa colonization by gargling with specific antibodies, p.371-374. In: Sim J.S. (Ed.), Egg Nutrition and Biotechnology. CAB International, Wallingford.

Chacana P.A., Terzolo H.R., Gutierrez Calzado E. \& Schade R. 2004. Tecnologia IgY o aplicaciones de lós anticuerpos de yema de huevo de gallina. Revta Med. Vet. 85:179-189.

Chen C.C., Tu Y.Y., Chen T.L. \& Chang H.M. 2002. Isolation and characterization of immunoglobulin in yolk (IgY) specific against hen egg white lysozyme by immunoaffinity chromatography. J. Agricult. Food Chem. 50:5424-5428.

Cullen P.A., Haake D.A., Bulach D.M., Zuerner R.L. \& Adler B. 2003. LipL21 is a novel surface-exposed lipoprotein of pathogenic Leptospira species. Infect. Immun. 71:2414-2421.
Cunningham T.M., Walker E.M., Miller J.N. \& Lovett M.A. 1988. Selective release of Treponema pallidum outer membrane and associated polypeptides with triton $\mathrm{x}-114$. J. Bacteriology 170:5789-5796.

Davison F., Magor K.E. \& Kaspers B. 2008. Structure and evolution of avian immunoglobulins, p.107-127. In: Davison F., Kaspers B. \& Schat K.A.(Eds), Avian immunology. Academic Press, London.

Devi C.M., Bai M.V., Lal A.V., Umashankar P.R. \& Krishnan L.K. 2002. An improved method for isolation of anti-viper venom antibodies from chicken egg yolk. J. Biochem. Biophys. Methods. 51(2):129-38.

Faine S., Adler B., Bolin C. \& Perolat P. 1999. Leptospira and leptospirosis. $3^{\text {rd }}$ ed. MediSci, Melbourne. 272p.

Ferreira Júnior Á., Santiago F.M., Silva M.V., Ferreira F.B., Macêdo Júnior A.G., Mota C.M., Faria M.S., Silva Filho H.H., Silva D.A., Cunha-Júnior J.P., Mineo J.R. \& Mineo T.W. 2012. Production, characterization and applications for Toxoplasma gondii-specific polyclonal chicken egg yolk immunoglobulins. Plos One 7(7):e40391. doi: 10.1371/journal. pone.0040391

Haake D.A. 2000. Spirochaetal lipoproteins and pathogenesis. Microbiology 146:1491-1504.

Haake D.A., Walker E.M., Blanco D.R., Bolin C.A., Miller M.N. \& Lovett M.A. 1991. Changes in the surface of Leptospira interrogans serovar Grippotyphosa during "in vitro" cultivation. Infect. Immun. 59:1131-1140.

Karlsson M., Kollberg H. \& Larsson A. 2004. Chicken IgY: utilizing the evolutionary advantage. World Poultry Sci. J. 60:341-348.

Koizumi N. \& Watanabe H. 2005. Leptospirosis Vaccines: past, present, and future. J. Postgraduate Medical 51:210-214.

Lafetá B.N. 2006. Perfil protéico da membrana externa de Leptospira interrogans sorovariedade Hardoprajitno. Dissertação de Mestrado em Medicina Veterinária, Universidade Federal de Minas Gerais, Belo Horizonte, MG. 36p.

Larsson A., Carlander D. \& Wilhelmsson M. 1998. Immune response in chicken with different amounts of antigen. Food Agricult. Immunol. 10:29-36.

Leslie G.A. \& Clem L.W. 1969. Phylogeny of immunoglobulin structure and function: immunoglobulins of the chicken. J. Exp. Med. 130:1337-1352.

Matsunaga J., Werneid K., Zuerner R.L., Frank A. \& Haake D.A. 2006. LipL46 is a novel surface-exposed lipoprotein expressed during leptospiral dissemination in the mammalian host. Microbiology 152:3777-3786.

Narat M. 2003. Production of antibodies in chickens. Food Technol. Biotechnol. 41:259-267.

Palaniappan R.U., Mcdonough S.P., Divers T.J., Chen C.S., Pan M.J., Matsumoto M. \& Chang Y.F. 2006 Immunoprotection of recombinant leptospiral immunoglobulin-like protein A against Leptospira interrogans serovar Pomona. Infect. Immun. 74:1745-1750.

Paul K., Manjula J., Deepa E.P., Selvanayagam Z.E., Ganesh K.A. \& Subbarao P.V. 2007. Anti-Echis carinatus venom antibodies from chicken egg yolk: isolation, purification and neutralization efficacy. Toxicon 50:893.

Pauly D., Dorner M., Zhang X., Hlinak A., Dorner B. \& Schade R. 2009. Monitoring of laying capacity, immunoglobulin Y concentration, and antibody titer development in chickens immunized with ricin and botulinum toxins over a two-year period. Poult. Sci. 88:281-290.

Pei J. \& Collisson E.W. 2005. Specific antibody secreting cells from chickens can be detected by three days and memory B cells by three weeks post-infection with the avian respiratory corona-virus. Develop. Comp. Immunol. 29:153-160.

Reilly M.R., Domingo R. \& Sandhu J. 1997. Oral delivery of antibodies: future pharmacokinetic trends. Clin. Pharmacokinetics 32:313-323.

Schade R., Stak C., Hendriksen C., Erhard M., Hugl H., Koch G., Larsson A., Pollmann W., Van Regenmortel M., Rijke E., Spielmann H., Steinbusch H. \& Straughan D. 1996. The production of avian (egg yolk) antibodies: IgY - The Report and Recommendations of ECVAM Workshop 21. ATLA 24:925-934.

Souza M.A., Castro J.R.,Tavares T.C.F., Soares P.M., Santos M.P., Silva H.O., Lima-Ribeiro A.M.C. 2012. Padronização e validação de ELISA indireto para o diagnóstico da leptospirose bovina. Biosci. J. 28:993-999. 
Svendsen L., Croeley A., Ostergaard L.H., StodulskI G. \& Hau J. 1995. Development and comparison of purification strategies for chicken antibodies from egg yolk. Lab. Anim. Sci. 45:89-93.

Surujballi O. \& Elmgren C. 2000. Monoclonal antibodies suitable for incorporation into a competitive enzyme-linked immunoabsorbent assay (ELISA) for the detection of specific antibodies to Leptospira interrogans serovar Pomona. Vet. Microbiol. 71:149-159.
Tini M., Jewll U.R., Camenisc G., Chilov D. \& Gassmann M. 2002. Generation and application of chicken egg-yolk antibodies. Comp. Biochem. Physiol. 131:569-574.

Zhang W.W. 2003. The use of gene-specific IgY antibodies for drug target discovery. Drug Discovery Today 8:364-371.

Warr G.W., Magor K.E. \& Higgins D.A. 1995. IgY: clues to the origins of modern antibodies. Immunology Today. 16:392-398. 